\title{
A NEW METHOD OF STUDYING THE IDEATIONAL BEHAVIOR OF MENTALLY DEFECTIVE AND DERANGED AS COMPARED WITH NORMAL INDIVIDUALS ${ }^{1}$
}

ROBERT M. YERKES

National Research Council, Washington, D. C.

In our various institutions for the treatment of mentally defective, deranged or criminalistic individuals, there is obvious and urgent need of methods which shall yield precise information concerning the ideational processes; for in large measure human conflict, inefficiency, and failure are due either to the lack of ideas or to their imperfect functioning. The comparative psychologist, interested as he necessarily is, in the genetic or developmental relations of ideational and other mental processes, seeks especially to devise methods which shall supply strictly comparable data concerning the characteristics and genetic relations of the various important mental processes and forms of behavior. It is one of his chief tasks to achieve more complete knowledge and a practical understanding of ideation through the study of its evolution in the race (phylogenesis) and of its development in the individual (ontogenesis). He views the psychological problems of psychiatry and psychopathology in the light of knowledge of mind and behavior which is generally considered irrelevant by the professional psychiatrist or psycho-pathologist. Yet here and there, much to the encouragement of those who believe firmly in the value of the comparative method and of the genetic descriptions of life which it yields, appear evidences that even those whose attention is monopolized by the practical problems of mental deficiency or disease are coming to see that no stage or condition of mental life or behavior can be understood or intelligently dealt with

1 This manuscript was written in 1916. 
in the absence of thorough-going knowledge of its history and of its immediate relations to varied life-processes.

Especially in the sphere of contact of psychology with the medical sciences, methods of research, as contrasted with practical tests, are sorely needed. Because of the difficulties of our practical tasks we are prone to aim rather too directly at useful results. Our tests are on the whole either too simple to yield reasonably accurate results, or they supply information too limited in its scope for safe interpretation and application. The method which I am about to describe is not a simple test, but instead a means of exploring certain of the ideational processes. It ultimately should yield results of practical value, but it will commend itself rather to those who wish a thorough understanding of reactive tendencies than to such as seek a rule of thumb for immediate use.

An experimental study of ideation may be (1) introspective, or (2) behavioristic, or (3) a combination of these two modes of observation. Since, while admitting the serviceableness of introspection, I am interested primarily in the study of behavior, the method which I have devised is behavioristic. But it should not be overlooked that it offers excellent opportunities for introspection whenever the subject is capable of such observation. I wish especially to emphasize the behavioristic character of the new method because physicians have too long ignored or neglected the scientific study of behavior, and this despite the fact that they might naturally be expected to take first place in the advance of our knowledge of human activities.

An appreciation of certain of the needs of information concerning ideational behavior having been forced upon me as psychologist in a hospital for the psychopathic I looked about for available methods of research. Only one promised to meet my requirements, and it, on close examination, proved to have so many shortcomings that I finally decided to use it as a basis for the development of a new procedure. The method to which I refer was devised by the psychiatrist and keen student of behavior, G. V. Hamilton. ${ }^{2}$

${ }^{2}$ Hamilton, G. V.: A study of trial and error reactions in mammals. Jour. Animal Behavior, 1911, 1, 33-66. 
Hamilton, in order to get knowledge of the reactive tendencies of normal and pathological, mature and immature human subjects in relation to those of infrahuman animals, has developed an apparatus and procedure at once ingenious and fruitful of practically and theoretically interesting and valuable results. He confronts his subject repeatedly with a certain situation. A compartment or room from which the subject seeks to escape is provided with four exit doors. In any given trial, only one of the four doors can be opened by the subject. The subject has no way of predicting which door will open. Only one of the four possible exists can be safely neglected, namely, the one which yielded escape in the immediately preceding trial, for the same door is not left unlocked twice in succession. As soon as a subject escapes through the appropriate exit, it is rewarded by the experimenter and after a certain interval returned to the compartment to try again to select the proper door. Thus, time after time, the behavior of a subject is observed in this definite and controlled situation.

The experimenter, as a result of repeated observations, discovers the various reactive tendencies of his subject and important characteristics of its ideational life. In the end his description of a given human or infrahuman subject's responses indicates the nature and degree of its ability to meet a situation which may be more or less adequately coped with according to the ideational capacity of the organism. Thus, certain persons, as well as certain lower animals, display the very ineffective method of trying the four doors at random, often the same one repeatedly. Yet other persons, or types of animal, exhibit the more satisfactory method of trying the doors in order from left to right, or from right to left, until the one which is unlocked is located. Still other subjects display a superior method in that they avoid the door which yielded egress in the previous trial and without repetition or waste of effort attack one, or if necessary all three, of the remaining doors.

Appreciation of the importance for the medical sciences, and especially for psychiatry, of Hamilton's method and of his results, the bulk of which are as yet unpublished, is just now 
beginning to develop; and it surely is not rash to predict that the kind of work which he inaugurated with mentally diseased and defective subjects more than ten years ago will shortly lead to important and far reaching improvements in the treatment of certain types of mental disorder. For after all it must be admitted, even by those who are most insistent on immediately and narrowly practical observational work, that the number, nature, and relations of our modes of adapting ourselves to the situations of life must be the chief diagnostic materials in case of many social and organic disturbances.

The method of Hamilton, which has been briefly described, presents a problem which is practically insoluble, yet whose solution may be approached in varying degrees, thus giving opportunity for the display of a great variety of reactive tendencies.

Taking Hamilton's procedure as my starting point, I devised an apparatus and technique which enable the experimenter to present to any subject-human or infrahuman, mature or immature, normal, defective, or diseased-problems the solution of which gives opportunity for ideational reaction, although not necessarily depending upon it. The problems which I finally decided to use may appropriately be called relational problems and the apparatus by means of which they are presented to a given subject I have rather inaptly named the multiple-choice apparatus.

The nature of a typical relational problem may be indicated by a simple example. Let us suppose that a group of like objects is placed before a subject. Some member of the group we shall define as the object to be selected or chosen by the subject, choice of it resulting in the obtaining of a reward, or the announcement of success. Let us further suppose that the right object, or the one to be chosen, may be adequately defined only in terms of its relation to the other members of the group. In case of a given problem, the relation might be middleness. Obviously, if the subject were told in advance, or by his own observation discovered, this definition, he should be able to select the right object immediately from any group 
which happened to be presented. To be sure, if the number of objects in the group became very great, the task of selection would be correspondingly difficult.

Now, as it happens, this relational method of studying ideational behavior has several points of merit for those comparative psychologists who seek to apply precise methods of studying behavior to the materials of the psychiatrist. These merits, it must be admitted, are not accidental, but instead result from the requirements which $I$ had in mind in devising problems, apparatus, and procedure. The most important of them may be described thus: (1) A series of problems ranging in difficulty from the very simple and easy to the extremely difficult may be selected, standardized, and presented, either in part or in entirety, to any given subject. (2) Each of these problems is completely soluble by a subject with excellent ideational capacity, although not necessarily by a given subject. (3) The attempts of a subject to solve a problem are readily recordable as forms of reaction, for the most part as definite choices of objects in a group. The experimenter may, however, make time-measurements and keep, if he so desires, detailed records of behavior between choices. (4) Introspective data supplementry to those recorded under (3) may often be obtained from human subjects. Especially after success in the selection of the right object has been attained, it is important to request of the subject, if linguistic reaction is possible, a definition of the right object or a description of the method of selecting it. (5) Graphic representations of the process of problem solution, ideational or otherwise, are possible. Such, for example, are curves of learning constructed on the basis of right or wrong choices. Coefficients or indices of ideational capacity may also be used. Likewise, formula descriptive of the mode or modes of reaction, reactive tendencies or methods of choice become available.

\section{APPARATUS}

The original form of multiple-choice apparatus, with which at the Psychopathic Department of the Boston State Hospital 
the relational method was given preliminary trial, consists of a bank of twelve similar wooden keys before which the subject can be seated. Each key has electrical connection with a signal apparatus (bell or buzzer) which serves to indicate to the subject success in locating the right key. This simple and crude apparatus is shown in use in the accompanying figures 1 and 2. Any one or all of the twelve keys may be presented to the subject in a given trial. As the figures indicate, keys not in use are placed in a vertical position by the experimenter, whereas those from among which the subject is required to select the right one remain in a horizontal position and may be pressed by the subject in his effort to locate the one which will cause the signal apparatus to respond.

Before describing the procedure or further discussing the method, I shall describe briefly an improved form of multiplechoice apparatus which has now replaced the original. ${ }^{3}$ The essential features of this improved model are: (1) A bank of twelve hard-wood keys which can be operated by the experimenter from one side of a screen and by the subject from the opposite side. (2) A signal and switch board on which are mounted twelve miniature lamps, each of which is connected with one of the keys. On the same switch board are mounted, also, twelve jacks, each of which is connected with one of the keys and may be connected with a small buzzer. (3) A wooden screen which serves to separate subject and experimenter and to prevent the former from seeing the movements of the latter and of thus being influenced in his selection of keys. (4) A box upon which the above parts are mounted and in which are housed the electrical mechanisms for the signal board.

This apparatus is shown fairly satisfactorily in figures 3,4 , and 5. Figure 3 is a rear view of the apparatus, showing the signal board with its twleve lamps and the jacks and plug by means of which any key may be connected with the buzzer. Beyond the signal board appear the metal clips, each numbered, with which the experimenter can either push out (expose to

This apparatus was constructed in the shop of the Harvard Psychological Laboratory. 


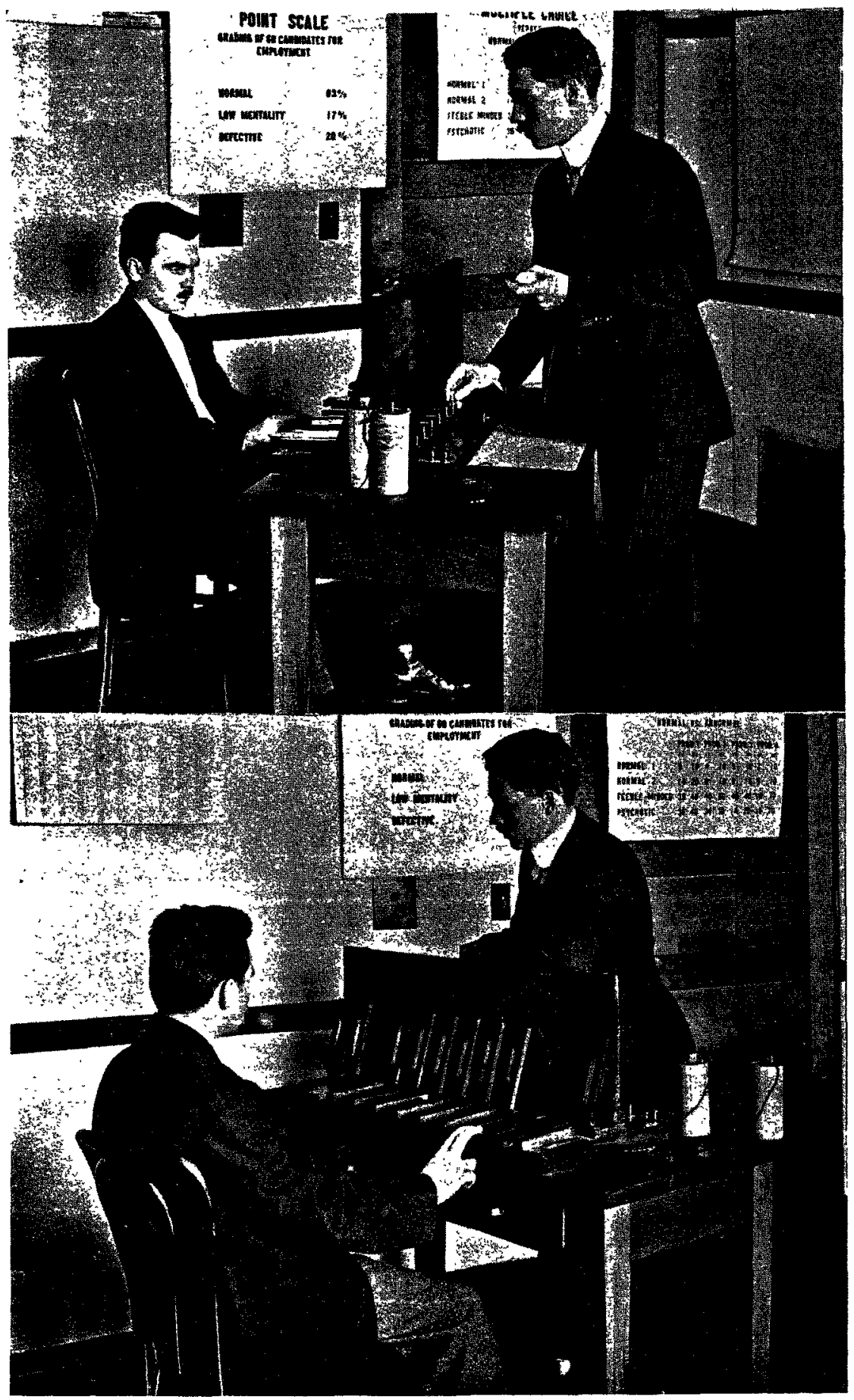

Figs. 1 AND 2. Figure 1, upper, and figure 2, lower; original multiple-choice apparatus, used in the Boston. State Hospital, Psychopathic Department. 


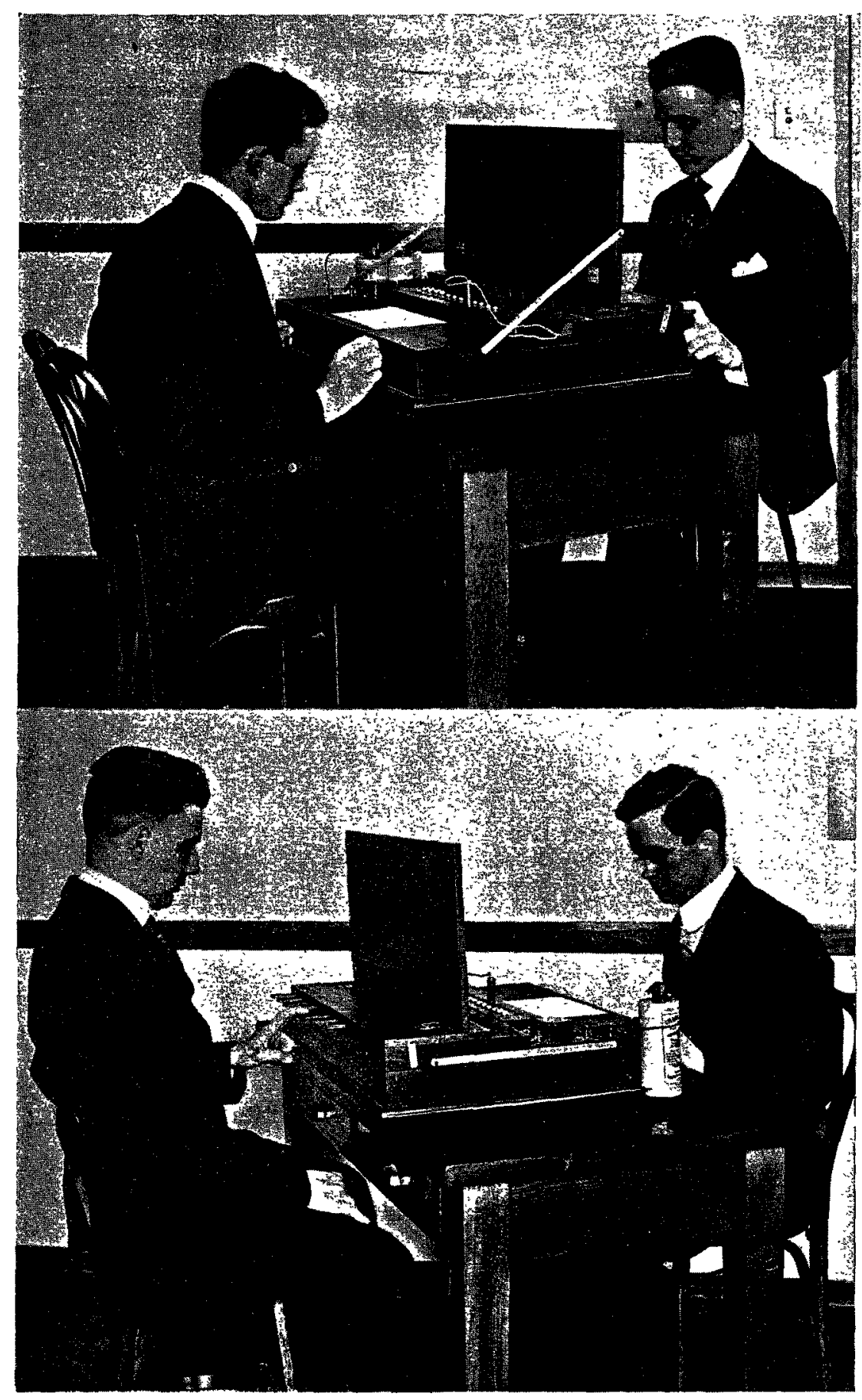

Frgs. 3 axd 4. Figure 3, upper, improved form of apparatus, rear view. Figure 4, lower, same, front view. 
view) or withdraw a given key. A small metal-cased buzzer and two binding posts for connections with dry batteries appear at the left end of the box. As this figure shows, the screen separating subject from experimenter is hinged so that when the apparatus is not in use, it may be folded back over the signal board to protect it from dust or from any possible mishap.

Figure 4 is a view of the apparatus from the front, showing it as it appears to the subject. The keys are numbered (on

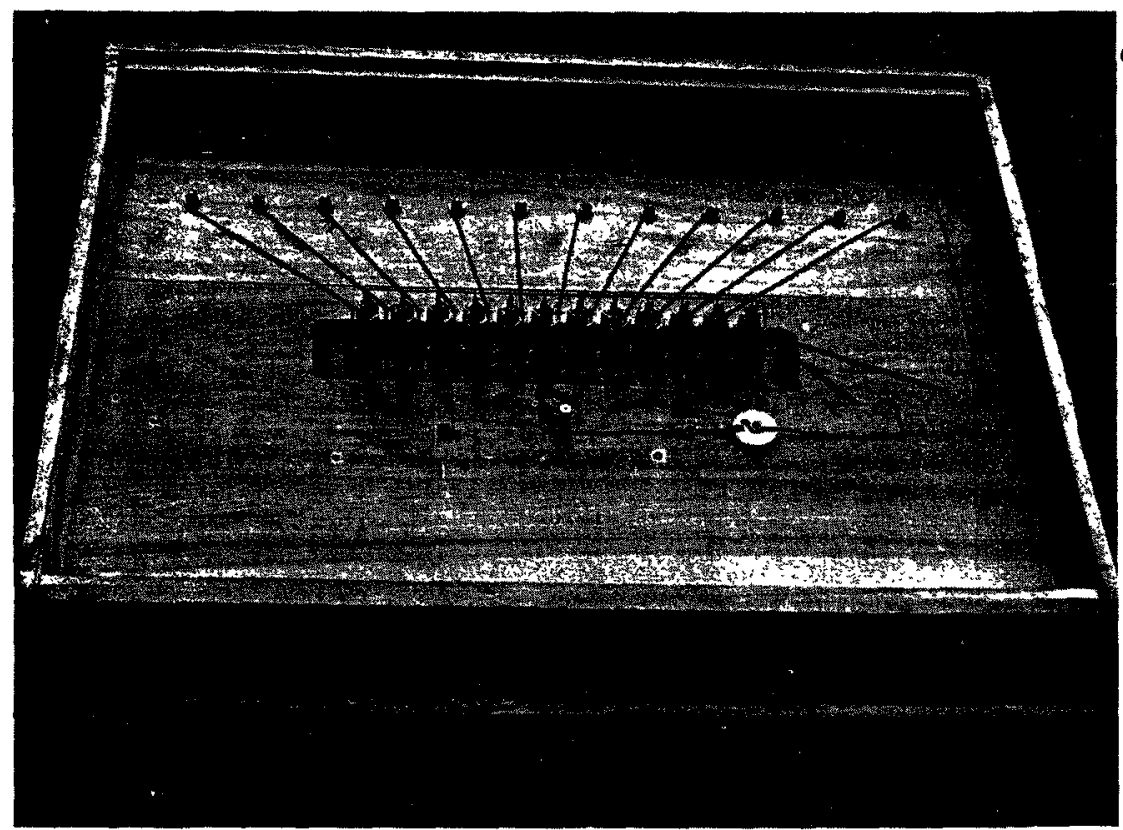

Figure 5. Apparatos from Beneath. Showing Wiring

the experimenter's side) from the right to the left, one to twelve. Keys nine to twelve are shown in their withdrawn position, that is, out of use or beyond the reach of the subject. Keys one to eight appear in position for use, that is, they project beyond their cover. The subject seated before the bank of keys is required merely to lightly depress the keys, one at a time. By so doing, he either makes a connection which causes the appropriate signal lamp for the key to flash, or in case the particular key happens to be the right one, it instead causes the buzzer to sound. 
Finally, figure 5 represents the apparatus as viewed from beneath, with the protecting floor removed. There appear in the foreground the row of jacks and a button resistance in the buzzer circuit. Beyond the jacks is a row of twelve lamp sockets, and the wires connecting these mechanisms with the several keys.

The apparatus, as thus designed and constructed, enables the experimenter to obtain accurate records of a subject's choices by following the flashes on the switch board.4

A brief statement should be offered with reference to the adaptation of the method for experimentation with infrahuman organisms and for the rapid testing of human subjects in connection with certain practical demands.

Multiple choice problems can be satisfactorily presented to a great variety of lower animals by means of a series of similar boxes, each of which is provided with an entrance and exit door. These boxes serve the same purpose as the bank of keys used for human subjects. The animal is required to select from a group of boxes whose entrance doors are open that one which bears a certain definite relation to the others, for example, the middle one. When this box is entered, the animal is rewarded with food, whereas when any other box is entered, instead of being rewarded with food, it is punished by being confined in that box for a certain interval and is then released and permitted to make another choice. This box type of multiple-choice apparatus has been used successfully with several birds and mammals. ${ }^{5}$ It may, of course, be used for human subjects quite as well as the key-board form, but the presentation of the problems requires much more time.

Münsterberg suggested a convenient adaptation of the multiple-choice method for rapid mental examining. On small cards he had printed three lines of capital letters. Each line contains at least two different letters, for example $\mathrm{A}$ and $\mathrm{O}$.

\footnotetext{
4 Electrical parts for the apparatus are supplied under the following numbers by the Western Electric Company: lamp no. 2-A, 4 volt; lamp cap no. 2-AY; lamp socket, no. 13; jack, no. 167; lamp cap tweezers, tool no. 112; lamp extractors, tool no. 116 .

${ }^{5}$ See references at end of paper.
} 
In case of some problems, the letters $A, O$, and $U$ appear in a single line. The letters are so arranged that the $O$, for example, bears in each line a certain special relation to the other letters of the group, as for instance, the relation of second from the right end. It is the task of the subject to whom this "relation test" is presented to discover the relation of the $O$ to the other letters on a given card. Different cards present relations of varying difficultness to discover and describe.

Yet another adaptation of the multiple-choice method has been made by the writer and the late C. S. Rossy. for use in an adult point scale which they constructed. ${ }^{6}$ In this case, circles and squares instead of letters are employed as symbols. A given card bears four lines of symbols, in each of which appear circles and one square. The relation of the latter to the circles is the same for each of the four lines. Experience indicates that the relational test has considerable practical value in mental examining as well as varied values as a method of research.

I wish, now, to describe as briefly as feasible the original multiple-choice procedure and certain features of the initial results obtained with normal and pathological subjects at the Psychopathic Hospital. The twelve-key apparatus described on page 373 was employed, and to each subject the following four problems were presented First problem, first key at the left; second problem, alternately the first key at the left and the first key at the right; third problem, third key from the left end; fourth problem, middle key.

Originally, the following explanation was made to the subject: "One key in the group will make a bell ring. Try to learn to find it. It will not be the same key twice in succession." The experimenter accompanied this statement by demonstration of the way in which the keys should be operated and of the fact that. a certain key in a given group would cause a bell to sound, whereas the pressing of any other key had no such result.

- Yerkes, Robert M., and Cecelio S. Rossy: A point scale for measuring the intelligence of adolescents and adults. Boston Medical and Surgical Jour., 1917, $176,564-573$. 
It was shortly discovered that this form of explanation tended to complicate the experiment. Consequently, the following briefer statement was substituted: "One of the keys in each group will make the bell ring. Try to find it the first trial each time."

Even this statement proved far from satisfactory, and it seems probable that in the long run it may be better to demonstrate the mode of operating the apparatus and to offer no statement concerning the nature of the problem or what is expected of the subject.

For each problem a series of ten settings of the keys was arranged. In each of these a definite group of keys was presented. These so-called settings of the keys for the various problems appear in the accompanying reproduction of record sheets, pp. 381-382. The sheets indicate that in case of problem 1, setting 1 , all twelve keys were presented to the subject, that in setting 2 , keys 5 to 10 were presented, and so on. Following the data of columns 1 to 3 in the record sheets, which give, respectively, the number of the trial, ${ }^{7}$ the keys in use, and the correct or signal key, appear the records of choices or reactions, that is, of keys pressed by the subject. Record sheet 1 presents the choices in each of the four problems for a normal man, while record sheet 2 similarly presents the results for a defective woman. The latter records, however, are not complete, since for problems $1,2,3$, and 4 more than one series of ten trials was given. Comparison of record sheets 1 and 2 indicate that the normal subject solved the problems quickly and with few reactions and trials, whereas the defective subject required a much larger number of trials and made several times as many choices or reactions as did the normal man.

The experimental procedure always involved the systematic presentation of the different settings from 1 to 10 in order. A series having been completed, the experimenter unless for some reason the observations had to be discontinued, returned to setting 1 and once more presented the settings in order from 1 to

"A given "setting" when presented to a subject is termed a "trial." 
10. As a rule, not more than fifty trials were given a subject in succession, and in some instances even although success had not been achieved the work was abandoned after thirty trials.

Record sheet 1

Name: H. R. Age: 43. Nationality: American. Date: January 30, 1914.

Diagnosis: Superior normal.

\begin{tabular}{|c|c|c|c|c|c|c|c|}
\hline \multicolumn{4}{|c|}{ PEOBLAM 1} & \multicolumn{4}{|c|}{ PROBLIMM 2} \\
\hline Setting & $\left|\begin{array}{c}\text { Keys } \\
\text { in use }\end{array}\right|$ & 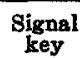 & REACTIONB & Setting & $\begin{array}{c}\text { Keys } \\
\text { in use }\end{array}$ & $\underset{\text { key }}{\text { Signal }}$ & REACTIONS \\
\hline 1 & $1-12$ & 1 & 6. 8.10 .12 .4 .2 .1 & 1 & $1-12$ & 1 & 5.7.9.11.3.1 \\
\hline 2 & $5-10$ & 5 & 6.7 .9 .5 & 2 & $5-8$ & 8 & 8 (Right key \\
\hline 3 & $10-11$ & 10 & $\begin{array}{l}10 \text { (Right key de- } \\
\text { fined after this } \\
\text { trial) }\end{array}$ & 3 & $3-10$ & $\mathbf{3}$ & 3 \\
\hline & $6-12$ & 6 & 6 & 4 & $1-12$ & 12 & 12 \\
\hline $\mathbf{5}$ & $2-10$ & 2 & 2 & 5 & $4-9$ & 4 & 4 \\
\hline 6 & $7-11$ & 7 & 7 & 6 & $2-11$ & 11 & 11 \\
\hline 7 & $3-11$ & 3 & 3 & 7 & $5-8$ & $\mathbf{5}$ & 5 \\
\hline 8 & $9-12$ & 9 & 9 & 8 & $3-10$ & 10 & 10 \\
\hline 9 & $8-10$ & 8 & 8 & 9 & $2-11$ & 2 & 2 \\
\hline 10 & $4-12$ & 4 & 4 & 10 & $4-9$ & 9 & 9 \\
\hline
\end{tabular}

\begin{tabular}{|c|c|c|c|c|c|c|c|}
\hline \multicolumn{4}{|c|}{ PBOBLEM 3} & \multicolumn{4}{|c|}{ PROBLEM 4} \\
\hline Setting & $\left|\begin{array}{c}\text { Keys } \\
\text { in use }\end{array}\right|$ & $\underset{\text { krey }}{\text { Signal }}$ & REACTIONS & Setting & $\left|\begin{array}{c}\text { Keys } \\
\text { in use }\end{array}\right|$ & $\underset{\substack{\text { Signal } \\
\text { key }}}{ }$ & BMACHONS \\
\hline 1 & $1-8$ & 3 & 4. 6. 8. 2.7.5. 3 & 1 & $1-5$ & 3 & $\begin{array}{l}3 \text { (Definition an } \\
\text { ticipated) }\end{array}$ \\
\hline 2 & $10-12$ & 12 & $\begin{array}{l}12 \text { (Right key de- } \\
\text { fined) }\end{array}$ & 2 & $4-12$ & 8 & $\begin{array}{l}8 \text { (Definition for } \\
\text { mulated) }\end{array}$ \\
\hline 3 & $2-10$ & 4 & 4 & 3 & $2-10$ & 6 & 6 \\
\hline 4 & $9-12$ & 11 & 11 & 4 & $|10-12|$ & 11 & 11 \\
\hline $\mathbf{5}$ & $3-8$ & $\mathbf{5}$ & 5 & 5 & $1-9$ & 5 & 5 \\
\hline 6 & $8-11$ & 10 & 10 & 6 & $3-5$ & 4 & 4 \\
\hline 7 & $4-10$ & 6 & 6 & 7 & $1-3$ & 2 & 2 \\
\hline 8 & $7-9$ & 9 & 9. & 8 & $2-12$ & 7 & 7 \\
\hline 9 & $5-12$ & 7 & 7 & 9 & $6-12$ & 9 & 9 \\
\hline 10 & $6-9$ & 8 & 8 & 10 & $8-12$ & 10 & 10 \\
\hline
\end{tabular}

As soon as problem 1 had been solved, problem 2 was presented, with a definite statement that a change had been made from the first problem to a new one. 
Record sheet 2

Name: B. T. Age: 18. Nationality: American. Date: May 12, 1914. Diagnosis: Defective delinquent

\begin{tabular}{|c|c|c|c|c|c|c|c|}
\hline \multicolumn{4}{|c|}{ PROBLEM 1} & \multicolumn{4}{|c|}{ PROBLEM 2} \\
\hline Setting & \begin{tabular}{|c} 
Keys \\
in use
\end{tabular} & $\underset{\text { key }}{\text { Signal }}$ & REACTIONB & Setting & $\begin{array}{c}\text { Keys } \\
\text { in use }\end{array}$ & $\underset{\text { key }}{\text { Signal }}$ & RHACTIONB \\
\hline 1 & $1-12$ & 1 & $\begin{array}{l}\text { 3. 4.5.8.7.6. } 9 . \\
\text { 10. } 1\end{array}$ & 1 & $1-12$ & 1 & 8. 4.7.6.2.3.1 \\
\hline 2 & $5-10$ & $\mathbf{5}$ & 7.9.10.8.8.7.5 & 2 & $5-8$ & 8 & 8 \\
\hline 3 & $10^{\circ}-11$ & 10 & 10 & 3 & $3-10$ & 3 & 10. 3 \\
\hline 4 & $6-12$ & 6 & 6 & 4 & $1-12$ & 12 & 1. 12 \\
\hline 5 & $2-10$ & 2 & $\begin{array}{l}\text { 4. 7. 8.6.9. 3. } 10 . \\
\text { 4. } 2\end{array}$ & 5 & $4-9$ & 4 & 4 \\
\hline 6 & $7-11$ & 7 & 7 & 6 & $2-11$ & 11 & 11 \\
\hline 7 & $3-11$ & $\mathbf{3}$ & 6. 3 & 7 & $5-8$ & $\mathbf{5}$ & 8. 6 \\
\hline 8 & $9-12$ & 9 & 12.11 .9 & 8 & $3-10$ & 10 & 10 \\
\hline 9 & $8-10$ & 8 & 8 & 9 & $2-11$ & 2 & 2 \\
\hline 10 & $4-12$ & 4 & $\begin{array}{l}4 \\
\text { etc. }\end{array}$ & 10 & $4-9$ & 9 & $\begin{array}{l}4.9 \\
\text { etc. }\end{array}$ \\
\hline \multicolumn{4}{|c|}{$\begin{array}{l}\text { No mistakes after twenty-sixth trial, } \\
\text { but failed to formulate definition. }\end{array}$} & \multicolumn{4}{|c|}{$\begin{array}{l}\text { No mistakes after nineteen trials. } \\
\text { Definition formulated. }\end{array}$} \\
\hline
\end{tabular}

\begin{tabular}{|c|c|c|c|c|c|c|c|}
\hline \multicolumn{4}{|c|}{ PROBLEM 3} & \multicolumn{4}{|c|}{ PROBLEM 4} \\
\hline Betting & $\begin{array}{c}\text { Keys } \\
\text { in use }\end{array}$ & 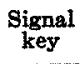 & RIIACTIONS & Setting & $\begin{array}{l}\text { Keys } \\
\text { in use }\end{array}$ & $\underset{\text { igey }}{\text { Signal }}$ & RFACTIONS \\
\hline 1 & $1-8$ & 3 & 4.3 & 1 & $1-5$ & 3 & 4. 1. 5. 3 \\
\hline 2 & $10-12$ & 12 & 11. 10.12 & 2 & $4-12$ & 8 & 6.7 .8 \\
\hline 3 & $2-10$ & 4 & 10.4 & 3 & $2-10$ & 6 & 5. 6 \\
\hline 4 & $9-12$ & 11 & 9. 12.10 .11 & 4 & $\mid 10-12$ & 11 & 12. 11 \\
\hline 5 & $3-8$ & $\mathbf{5}$ & 6.4.8.7.3. 5 & 5 & $1-9$ & 5 & 5 \\
\hline 6 & $8-11$ & 10 & 10 & 6 & $3-5$ & 4 & 3.4 \\
\hline 7 & $4-10$ & 6 & 5.7 .10 .6 & 7 & $1-3$ & 2 & 1. 3.2 \\
\hline 8 & $7-9$ & 9 & 9 & 8 & $2-12$ & 7 & 6. 8.2.12.4.3.7 \\
\hline 9 & $5-12$ & 7 & 7 & 9 & $6-12$ & 9 & 10. 11.6 .9 \\
\hline 10 & $6-9$ & 8 & 8 & 10 & $8-12$ & 10 & $\begin{array}{l}\text { 11. } 9.10 \\
\text { etc. }\end{array}$ \\
\hline \multicolumn{4}{|c|}{$\begin{array}{l}\text { No mistakes after seven trials. } \\
\text { Definition formulated. }\end{array}$} & \multicolumn{4}{|c|}{$\begin{array}{l}\text { Failed to solve problem. } \\
\text { Given thirty trials. }\end{array}$} \\
\hline
\end{tabular}


A problem was considered solved as soon as a subject stated correctly the relation of the right key to the other members of the group, and the number of trials preceding the first initially correct trial after which no errors appeared was taken as a measure of the rapidity of solution. Either this datum or the total number of reactions may be used as the score. In case a subject failed to define the right key correctly, observation was continued until ten successive correct trials had been recorded, for occasionally it happens that a subject who is capable of fulfilling the demands of the situation by selecting the proper mechanism each time is quite incapable of formulating a description of method or a definition of the right key.

For the purpose of thoroughly trying out the method, of obtaining results for perfecting the technique and improving the apparatus, observations were made on approximately fifty normal subjects, all of whom were adults although varying widely with respect to education and professional training; on thirteen mental defectives, either adolescents or adults; and on somewhat more than fifty mentally deranged and diseased individuals, including cases of dementia praecox, manic depressive insanity, general paralysis, and drug psychoses. It is not the purpose of this report to present in detail the results of these observations, but instead merely to describe the method fully for the benefit of those who may wish to use it and to indicate certain general features of the results obtained with the groups of subjects referred to above. A complete account of the reaction of a subject to multiple-choice problems is given by the detailed records and supplementary notes made during experimentation, of which record sheets 1 and 2, pages 381 and 382 are offered as samples.

Obviously, it is not feasible to publish these detailed case records. Instead, it is necessary to find some way of summarizing the results. Analytic study of the data led to the following conclusions concerning feasible modes of treatment. Statistical data, although of considerable value, should by no means take the place of careful analysis and detailed description of individual reactions. Among the observational data which promise to be 
useful are (a) the number of trials necessary for the solution of a given problem; (b) the total number of reactions, that is, the number of keys operated in the several trials necessary for the solution of a problem; (c) the number of repetitions, that is, the number of times keys are used more than once in a given trial; (d) the number of ideas indicated by the objective records of response or by the introspection of the subject; (e) the method or methods of reaction, as for example, systematic use of the keys from the left to the right end of a group, or from right to left, or the regular trial of the even keys in order, or of the odd keys in order, random or haphazard procedure with repeated use of the same keys, etc.; (f) mental condition, that is, the general mental status or attitude in connection with reactions. It may obviously be one of confusion, of forgetfulness, or of definite insight, clearness, planning. (g) Types of reaction, such for instance as the tendency to begin at a certain point in each group or to favor a particular key or combination of keys. Such types of reaction are numerous and as yet insufficiently studied to warrant an attempt to list and evaluate them. (h) Formulation of definition. In varying degrees, subjects are capable of explaining their solution of a given problem. At one extreme are found individuals who although capable of respondirg correctly and thus of meeting the technical requirements for the solution of a problem, are yet utterly incapable of describing their method or even of stating the relational problem which they have solved in motor terms. Individuals incapable of defining the right key appear among normal as well as among defective and pathological subjects.

In multiple-choice experiments it is obviously essential that the observer keep complete records not only of the subject's reactions but also of his verbal comments or incidental bits of introspection and of such introspection as is elicited by questioning. As soon as a record has been completed, the results should be carefully analyzed.

There are presented in table 1 certain statistical data for forty-eight normal subjects, grouped in four categories. The primary classification is according to sex, but each sex group 
is divided into individuals of superior native ability and educational opportunity as contrasted with those of ordinary to poor native ability and education. For each of the four groups the average score, number of reactions and number of repetitions is presented for the problems described on page 379, and numbered in the table, 1 to 4 .

TABLE 1

Summary of results for normal subjects

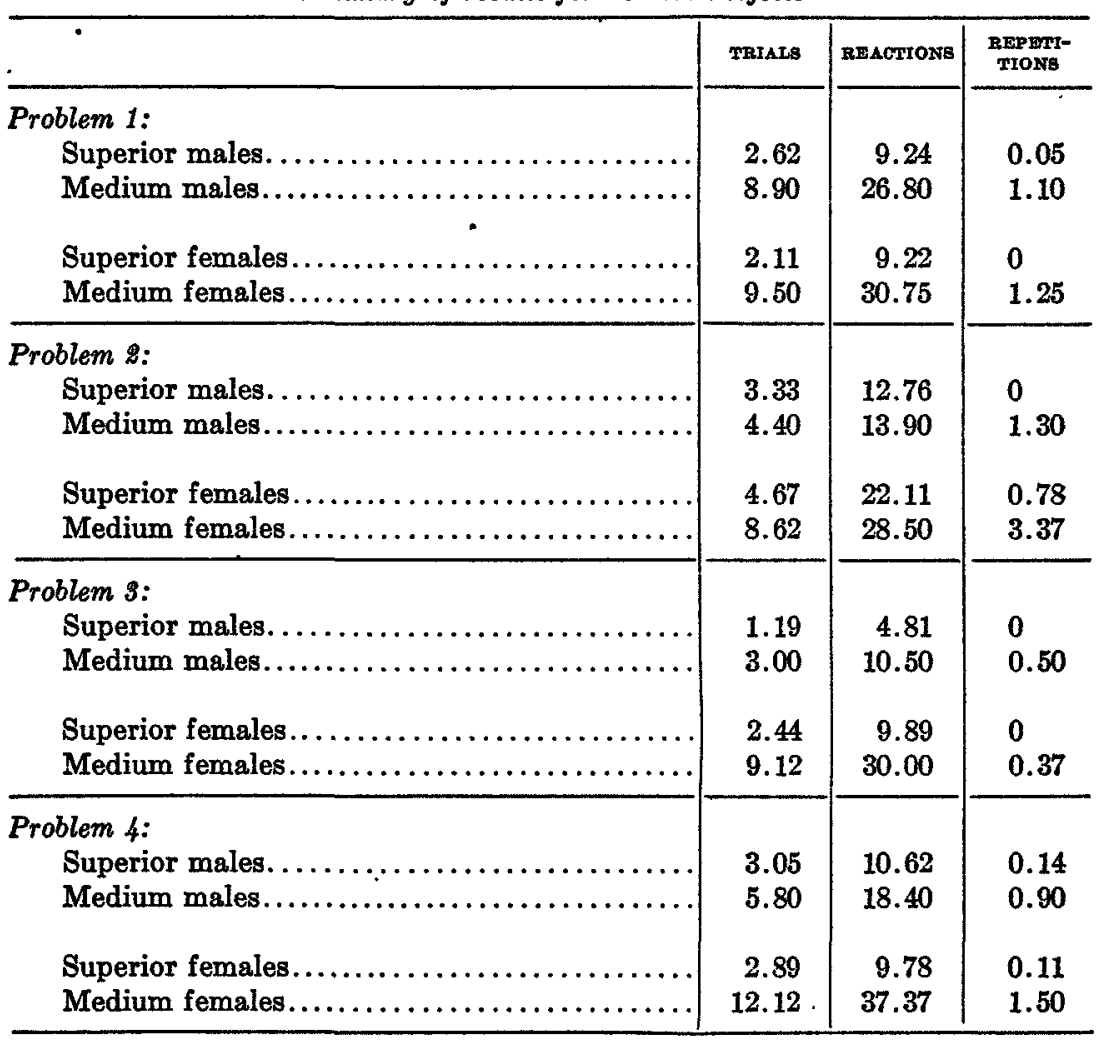

Particularly striking, in this table, are the numerical differences for the subdivisions of the sex groups. Unquestionably, education has much to do with the facility in the use of ideas exhibited by the superior individuals. Yet is it probable that native ability also has much to do with the contrasted results of the several groups. It should also be noted that the frequency of 
repetition is very much greater for the males and females of medium ability than for those of superior ability.

It may be remarked that the responses of a subject to a series of multiple-choice problems, no matter how the results be analyzed later or what significance be attached to them in the light of statistical data are surprisingly illuminating to the observer, for they indicate in a remarkable manner the ideational characteristics and efficiency of the subject. It seems to the writer fairly clear that some such procedure as this relational method may profitably be adapted to the needs of the mental examiner as a means of measuring for practical purposes such ideational characteristics of human subjects as number of ideas, their quickness of development and value.

TABLE 2

Summary of results for mentally defective subjects

\begin{tabular}{|c|c|c|c|}
\hline & TRIALS & RBACTIONS & $\begin{array}{l}\text { REPBTI- } \\
\text { TIONS }\end{array}$ \\
\hline Problem $1 \ldots \ldots \ldots \ldots \ldots \ldots \ldots \ldots \ldots \ldots \ldots \ldots \ldots \ldots$ & 9.9 & 26.0 & 0.4 \\
\hline Problem $2 \ldots \ldots \ldots \ldots \ldots \ldots \ldots \ldots \ldots \ldots \ldots$ & 17.0 & 35.5 & 0.5 \\
\hline Problem $3 . \ldots \ldots \ldots \ldots \ldots \ldots \ldots \ldots \ldots \ldots \ldots \ldots$ & 5.6 & 16.4 & 0.1 \\
\hline Problem $4 \ldots \ldots \ldots \ldots \ldots \ldots \ldots \ldots \ldots \ldots \ldots \ldots \ldots$ & 23.7 & 73.7 & 4.2 \\
\hline
\end{tabular}

By contrast with the results for normal subjects, there are presented in table 2 comparable data for thirteen mentally defective individuals, who, however, do not constitute a homogeneous group, since they exhibited varying degrees as well as kinds of mental deficiency. It will be observed that, in general, the figures for the group are larger than those for any one of the four groups of normal subjects and that problem 4, which for the normal individuals proved on the whole slightly more difficult than the others, required a large number of trials and reactions involving many repetitions in case of the defectives. Intensive study of such differences is sure to prove fruitful of results valuable to genetic psychology and also to psycho-pathology.

Especially promising of valuable results, as indicated by the data thus far accumulated, are comparisons of the reactions of normal children, ranging in age from three years onward, 
with those of various sorts and degrees of mentally defective individual.

It has not seemed worth while to present statistical data for the group or groups of mentally deranged cases observed. Averages, it appears, are rather more likely to conceal than to reveal the significant facts. The group is almost hopelessly heterogeneous, for in addition to individual, age, race, sex, educational, and social psychological differences, there appear the induced differences of mental disease. Moreover, even when an attempt is made to lessen this heterogeneity by classifying the subjects according to diagnosis into such groups as dementia praecox, general paralysis, and so on, the degree of heterogeneity is still extremely great because the various cases were studied in different stages of the development of their diseases. Chiefly for this reason it has been decided to present four reasonably typical cases instead of statistical data. These cases are hereafter designated by initials as follows: A. C., female, aged twenty-four, dementia praecox (hebephrenic); S. W., female, aged forty-eight, manic depressive (depression); S. S., male, aged thirty-six, general paralysis (with insight); C. C., male, aged fifty-one, Korsakoff's psychosis.

For each of these subjects there are presented in table 3 the detailed records of reaction to problem 2 , in which the right key is definable as alternately the first key at the left end of a group and the first at the right end of a group. At the head of the table are indicated the ten successive settings of keys, S.1 to S.10. The keys presented and the right key appear under the number of the setting. Thus in S.1 all twelve (1-12) were presented and the first key (1) was the right one. The first vertical column of the left presents the number of trials in groups of ten. For each trial the numbers of the keys depressed appear in the several vertical columns. Subject A. C., for example, in his tenth trial (setting 10) depressed in order keys 4. 5. 6. 7. 8. 9. In his fiftieth trial (also setting 10) he depressed key 9 immediately.

The records of response speak clearly enough for themselves. The dementia praecox patient A. C., thought aloud, 
TABLE 8

Results for mentally diseased cases

Problem 2

\begin{tabular}{|c|c|c|c|c|c|c|c|c|c|c|}
\hline TrRuzs & $\underset{1-12(1)}{s .1}$ & $\underset{5-8}{\text { S. }} \mathbf{2}(8)$ & $\begin{array}{c}\text { S. } \\
\text { 3-10 } \\
\text { (3) }\end{array}$ & $\underset{1-12.4}{\text { S. }}$ & $\begin{array}{c}\text { S. } \\
4-9 \\
4(4)\end{array}$ & $\begin{array}{c}8.6 \\
2-11(11)\end{array}$ & $\begin{array}{r}\text { S. } \\
5-8(5)\end{array}$ & $\begin{array}{c}\text { 8. } 8 \\
3-10(10)\end{array}$ & $\stackrel{8}{8}, 9$ & $\underset{4 \rightarrow-9}{8 .}(9)$ \\
\hline \multicolumn{11}{|c|}{ A. C., Dementia praecox (Hebephrenic). Female, age twenty-four } \\
\hline $1-10$ & 1 & 5.6 .7 .8 & 10.3 & $\mid \begin{array}{l}1.5 .11 .3 . \\
2.4 .5 .6 .7 . \\
8.9 .10 .11 . \\
12\end{array}$ & 4 & 2. 11 & 5 & 10 & 2 & $\begin{array}{l}\text { 4. 5. 6. } 7 . \\
\text { 8. } 9\end{array}$ \\
\hline $\begin{array}{l}11-20 \\
21-30\end{array}$ & 2.1 & 5.8 & 3 & 1. 12 & 9. 4 & 9. 11 & 8. 5 & 1. 3. 10 & 11.2 & 4.9 \\
\hline $\begin{array}{l}21-30 \\
31-40\end{array}$ & $\begin{array}{l}12.1 \\
12.1\end{array}$ & $\begin{array}{l}8 \\
5.8\end{array}$ & $\begin{array}{l}3 \\
10.3\end{array}$ & $\begin{array}{l}11.12 \\
12\end{array}$ & & $\mid \begin{array}{ll}2 . & 11 \\
2 . & 11\end{array}$ & $\begin{array}{l}5 \\
8.5\end{array}$ & $\begin{array}{l}10 \\
10\end{array}$ & $\mid \begin{array}{l}2 \\
11.2\end{array}$ & $\begin{array}{l}9 \\
4.9\end{array}$ \\
\hline $41-50$ & 12. 1 & 5. 8 & 3 & 12 & 9.4 & 11 & 7. 5 & 10 & 11.2 & 9 \\
\hline
\end{tabular}

S. W., Manic depressive (Depression). Male, age forty-eight

\begin{tabular}{|c|c|c|c|c|c|c|c|c|c|c|}
\hline $1-10$ & $\mid \begin{array}{l}\text { 2. } 7.5 .6 .4 . \\
9.8 .10 .11 . \\
5.2 .3 .4 .5 . \\
1\end{array}$ & 5.7 .6 .8 & 4.3 & $\begin{array}{l}\text { 2. 4. 3. } 7.6 . \\
5.1 .9 .10 . \\
12\end{array}$ & 4 & [3. 2.9. 11 & 5 & {$\left[\begin{array}{l}9.3 .4 .7 . \\
9.10\end{array}\right.$} & 3. 2 & 9 \\
\hline $11-20$ & 5.4 .1 & 5.8 & 3 & $\begin{array}{l}9.6 .2 .4 .5 . \\
1.10 .12\end{array}$ & 4 & 4. 2.7. 11 & 5 & 3. 4. 6. 10 & 10.2 & 4. 9 \\
\hline $21-30$ & 1 & 5.8 & 4.3 & 3. 1.2.5. & 9. 7.4 & 2. 4.11 & 5 & 3. 10 & 2 & 9 \\
\hline
\end{tabular}


S. S., General Paralysis. Male, age thirty-six

\begin{tabular}{|c|c|c|c|c|c|c|c|c|c|c|}
\hline $1-10$ & $\begin{array}{l}\text { 2. 3. 4.5. } 6 . \\
\text { 7. 8. } 9.10 . \\
11.12\end{array}$ & 5. 6.7.8 & $\begin{array}{l}10.9 .8 .7 \\
6.5 .4 .3\end{array}$ & 12 & & & & & & \\
\hline \multicolumn{11}{|c|}{ C. C., Korsakoff's psychosis. Male, age fifty-one } \\
\hline $1-10$ & 1 & 5. 8 & 3 & 12 & 6. 4 & $\begin{array}{l}6.5 .2 .3 . \\
4.5 .6 .7 \\
8.9 .10 .11\end{array}$ & 5 & 3. 10 & 11.2 & $\begin{array}{l}\text { 7. } 4.6 .5 . \\
8.9\end{array}$ \\
\hline $11-20$ & 1 & 5.8 & 5. 7.6.3 & 12 & 4 & $\begin{array}{l}9.2 .4 .3 . \\
5.6 .7 .8 . \\
9.10 .11\end{array}$ & 8.7 .5 & 10 & 2 & $\begin{array}{l}\text { 7. } 5.6 .4 . \\
8.9\end{array}$ \\
\hline $21-30$ & 1 & 7. 5.8 & 3 & 12 & 6. 9.4 & 11 & 7.8 .5 & $\begin{array}{l}\text { 7. 6. 4. } 3 . \\
\text { 8. 9. } 10\end{array}$ & 2 & 9 \\
\hline $31-40$ & 1 & 5. 8 & 8. 10. 3 & 1. 12 & 7. 6.4 & 2. 3. 10.11 & 7.6 .5 & $\begin{array}{l}\text { 7.6.5. } 4 \\
\text { 3.8.9.10 }\end{array}$ & 10. 11.2 & 9.4 \\
\hline $41-50$ & 12. 1 & 7. 5. 6. 8 & 10. 3 & 12 & 4 & 11 & 7. 6. 5. 8 & $\begin{array}{l}\text { 5.3. 4. } 6 . \\
\text { 7. 8.9.10 }\end{array}$ & 2 & 9 \\
\hline
\end{tabular}


saying "It's the first one," "It's the last one," "It's the first one again." In trial 8 , she exhibited an interesting ideational response by pressing the end keys 3 and 10,. simultaneously. At various times in the continuous series of fifty trials given to this subject, she seemed on the verge of solution of the problem. Thus, for example, after trial 6 she reacted correctly three times in succession and asked, shortly, why the end keys were used. But in subsequent trials, her responses clearly indicated inability to grasp the principle of alternation, and finally after fifty unsuccessful trials, the method was explained to her in order that the next problem might be presented. She nearly succeeded in solving problem 1; failed on problems 2,3 , and 4 . In her work a slight improvement appeared because of memory for the particular settings. She, however, exhibited little insight, talked freely and often foolishly, was deluded, and gave evidence of inferior mentality, apart, perhaps from the deteriorating effects of her mental disease.

S. W., the subject of depressive insanity, worked without insight and in ways extremely difficult to predict or to account for in ideational terms. He failed to solve, within the number of trials allowed, any of the four problems. At the end of his twentieth trial with problem 2 , he remarked "They change all the time. I don't see how anybody could tell," and still later he volunteered "It's chance." In the three series of trials given to him in problem 2, he showed marked improvement, especially in the direction of lessening the number of reactions per trial. This is precisely what appears in low grade defectives among human subjects and in such animals as the monkey, pig, and cat. A careful comparative study of the results for various types of animal, grades of mental deficiency, and conditions of mental deterioration should prove quite as illuminating to the psycho-pathologist as to the genetic psychologist.

S. S., the general paralytic, worked on a wholly different plane from that of the other subjects, for he possessed insight, and although annoyed by the demand for intellectual effort, as a favor to the experimenter he worked faithfully at the multiple- 
choice problems. Problem 1, he solved immediately, grasping the idea of first at the left during the first trial. Problem 2 required three trials, in each of which, as the data of table 3 indicate, ideas are evident. Thus, for instance, he avoided key 1 in his first trial because it had been the correct key in problem 1. He then systematically tried each key in order from 2 to 12 , and having eliminated the others, pressed key 1. Similarly, in the second trial, he worked systematically from left to right, through the group of keys. In the third trial, pursuant of the idea suggested by success with the last key in trial 2 , he pressed key.10 first, and thence worked systematically toward the left, until he achieved success. In the fourth trial, he reacted at once correctly on the basis of the idea of first at the right end, and previous to his reaction he formulated the definition "First extreme left, then extreme right." The third problem he solved immediately, formulating the definition after the first trial and putting it to the test in the second trial. Thefourth problem baffled him. Failure irritated and discouraged him. With urgence he continued to work through thirty-seven trials. He formulated the definition "Middle key of all keys down" after thirty-five trials.

It is peculiarly interesting and puzzling that a subject with the insight and ideational capacity of S. S. should have had so much difficulty with problem 4 after solving the other three problems easily. This result is sharply at variance with the data yielded by normal subjects, for even children of six to ten years have, so far as data are available, as a rule solved problem 4 quickly. It is natural to suppose that fatigue may have had much to do with the general paralytic's difficulties with this problem. His records indicate that he tried out a considerable number of complex relational hypotheses.

C. C. exhibited no enthusiasm for the experiment. He worked patiently, and after fifteen trials solved the first problem. In the second problem, fifty trials failed to give indication of approaching solution. He mostly tried the end keys, but he was not consistent in this, and the results indicate that he failed to discover that only the end keys yield success. The results, unlike those for S. W., show no lessening of the number of reac- 
tions with successive trials. In this respect they are in harmony with those obtained from other cases of alcoholic psychoses. Almost without exception such patients have extreme difficulty with ideational tasks. Their ideational efficiency is apparently greatly impaired by the deteriorating effects of alcohol.

TABLE 4

Suggested problems to be used with multiple-choice apparatus and method for testing human or other subjects

Problem 1. The same key in each trial (key or mechanism No. 5 from the left end of apparatus).

$1-6(5) ; 3-12(5) ; 4-6(5) ; 5-9(5) ; 2-10(5) ; 4-5(5) ; 4-10(5) ; 3-6$ (5); $1-8(5) ; 5-10(5)$.

Problem 2. The first mechanism at the left end of a group.

6-12 (6); 11-12 (11); 3-11 (3); 1-5 (1); 4-11 (4); 10-12 (10); 5-9 (5); 2-12 (2); 8-11 (8); 7-12 (7).

Problem 3. The middle mechanism in a group. $1-7(4) ; 10-12(11) ; 6-10(8) ; 1-11(6) ; 1-3(2) ; 4-10(7) ; 1-9(5) ; 9-11$ (10); 1-5 (3); 6-12 (9).

Problem 4. The third mechanism from the right end in a group. $1-6(4) ; 5-8(6) ; 3-12(10) ; 1-3(1) ; 7-11(9) ; 2-10(8) ; 1-7(5) ; 2-4$ (2); 2-9 (7); 1-5 (3).

Problem 5. Alternately, the first mechanism at the left end and the first mechanism at the right end of groups.

$8-12(8) ; 1-10(10) ; 3-8(3) ; 6-9(9) ; 1-9(1) ; 3-5(5) ; 7-11(7) ; 5-12$ (12); $2-8(2) ; 4-6(6)$.

Problem 6. The next mechanism at the left each time, beginning with mechanism No. 12 , that is, progressively from the right toward the left end of the apparatus.

$10-12(12) ; 6-12(11) ; 3-10(10) ; 8-12(9) ; 8-10(8) ; 1-9(7) ; 5-8(6)$ 4-9 (5); 2-11 (4); 3-7 (3).

Problem 7. The mechanism to the left of the middle mechanism of a group. $6-12(8) ; 3-5(3) ; 8-12(9) ; 1-9(4) ; 2-12(6) ; 10-12(10) ; 5-11(7)$; 1-5 (2); 3-9 (5); 1-3 (1).

Problem 8. Alternately, the second mechanism from the right end of a group and the second mechanism from the left end of a group. $6-12(11) ; 2-5(3) ; 1-8(7) ; 5-9(6) ; 1-5(4) ; 4-12(5) ; 5-10(9) ; 9-11$ (10); $2-9(8) ; 1-5(2)$.

Problem 9. The mechanism to the right of the mid-point in an even group, or the mechanism at the right end of the first half of a group consisting of an even number of mechanisms.

$3-10$ (7) ; 1-4 (3); 2-7 (5); 1-2 (2); 3-12 (8); 8-11 (10); 5-12 (9); 1-10 (6); 1-6 (4); 11-12 (12).

Problem 10. Alternately, the mechanism at the left of the middle mechanism and the mechanism at the right of the middle mechanism. $1-7(3) ; 8-12$ (11); 2-10 (5); 10-12 (12); 1-9 (4); 3-9 (7); 1-3 (1); $6-10(9) ; 6-12(8) ; 3-7(6)$. 
SUGGESTIONS FOR THE FURTHER USE OF THE MULTIPLECHOICE METHOD WITH HUMAN SUBJECTS

It is recommended that the improved form of the key-board apparatus be used for human subjects except where comparison of results with those obtained with lower animals is contemplated. In the latter case, it seems advisable to use some form of box mechanism for human as well as infrahuman subjects. Such mechanisms have been described by the writer in various reports of results. ${ }^{8}$

It is further recommended that the ten relational problems of table 4 be thoroughly tried out with a view to evaluation, revision or substitution, standardization and arrangement in servicable order. Following the designation of each problem by definition of the right key is a series of ten settings. The total number of keys used in each of these series is 60 . This list of problems with the settings suggested, was originally published in the Journal of Animal Behavior, 1917, 7, pp. 27, 28. Discrepancy will be noted between the series as published here and in the Journal of Animal Behavior, as follows: In the case of problem 4, setting 8 was originally mis-printed as 3-5 (2). It should have read 2-4 (2). In the case of problem 9, setting 5 was originally printed 3-12 (11). It should have been 3-12 (8). Setting 9 was originally printed $5-10$ (8). It should have been 1-6 (4).

\section{BIBLIOGRAPHY OF MUTIPLE-CHOICE METHOD TO 1921}

Ymrkes, Roвmai M.: The study of human behavior. Science, 1914, xxxix, $625-633$.

Cobdrn, Charles A., and Ymrkes, Robmp M.: A study of the behavior of the crow Corvus Americanus Aud. by the multiple choice method. Jour. Animal Behavior, 1915, v, 75-114.

Ymakes, Robert M., aND CoBuRn, Chardes A.: A study of the behavior of the pig Sus scrofa by the multiple choice method. Jour. Animal Behavior, $1915, \nabla, 185-225$.

Hamlion, G. V.: A study of perseverance reactions in primates and rodents. Behavior Monographs, 1916, iii, No. 13, 65 pp.

\footnotetext{
See especially Jour. Animal Behavior, 1917, 7, 11-28, and Behavior Monographs, 1916, 3, No. 1, IV +145 Pp.
} 
BURTT, HanoLd E.: A study of the behavior of the white rat by the multiple choice method. Jour. Animal Behavior, 1916, vi, 222-246.

YERKES, ROBERT M.: The mental life of monkeys and apes: a study of ideational behavior. Behavior Monographs, 1916, iii, No. 1, iv +145 .

Yerkes, RoBerT M.: Methods of exhibiting reactive tendencies characteristic of ontogenetic and phylogenetic stages. Jour. Animal Behavior, 1917, vii, 11-28.

Yerkes, Robert M., and Rossy, Cecelio S. A point scale for the measurement of intelligence in adolescent and adult individuals. Boston Med. and Surg. Jour., 1917, clxxvi, 564-573.

MAODowaLL, E. C.: Reports on investigations in progress: Modifiability of the germ-plasm by alcohol. Carnegie Institution of Washington, Yearbook, No. 18, 1919, 124-129.

MACDoweLL, E. C.: The influence of parental alcoholism upon habit formation in albino rats. Proceedings of the Society for Experimental Biology and Medicine, 1919, xvi, 125-126.

MacDowerl, E. C.: Results of the multiple choice training. Carnegie Institution of Washington, Yearbook, No. 19, 1920, 118-122.

BAGG, HALsEY J.: Individual differences and family resemblances in animal behavior: A study of habit formation in various strains of mice. Archives of Psychology, 1920, No. 43, 58 pp. 